\title{
Performance of Interline Unified Power Quality Conditioner (IUPQC) With PI, Fuzzy and ANFIS Controllers
}

\author{
A Navya, A Panduranga Rao, L Shanmukha Rao
}

\begin{abstract}
Several artificial intelligent control schemes are highly used in several applications, in that ANFIS controller has been greatly recognized due to enhanced performance over the classical PI and Fuzzy controllers. At present the multi-feeder power distribution system is deteriorated with continuity of supply and poor power quality standards. In this multi-feeder distribution system, it is a regular consumer related issue which is acquired due to malfunctioning of massive non-linear loads. These loads create the voltage or current imperfections on distribution networks which disrupts the power quality of distribution system. An efficient and reliable active compensation scheme is used for attaining enhanced power quality features at PCC of multi-feeder distribution system with effective control functions. The Multi-Feeder Unified Power Quality Compensator (MF-UPQC) is optimal choice for attaining enhanced power quality features and it is a combined shunt or series compensator driven by common DC-link. This paper recommends the Adaptive Neuro-Fuzzy Intelligent Controller (ANFIS) based prediction technique for generation of optimal switching states to enhance performance of proposed MF-UPQC to compensate all voltage-current $P Q$ imperfections. The performance of proposed MF-UPQC is verified by classical PI, Fuzzy and proposed ANFIS control functions by using MATLAB/SIMULINK tool and results are conferred with proper comparisons.
\end{abstract}

Keywords: Adaptive Neuro-Fuzzy Inference System, Hybrid-Fuzzy Logic Controller, Multi-Feeder Distribution System, Fuzzy-Logic Controller, Power Quality Improvement; PI Controller, Total Harmonic Distortion (THD).

\section{INTRODUCTION}

Economic growth of any nation depends upon the reliable and quality of Electrical power availability to industries and agricultural sector. With growing industries and agriculture demand of electric power utility are striving hard to maintain greater power-quality standards in electric power supply [1]. In addition, the increased utilization of power electronics devices in electric utility system causes poor power quality and affects the Electric Power Systems.

Revised Manuscript Received on February 05, 2020.

* Correspondence Author

A Navya, Studying IV, B.Tech, EEE, Kallam Haranadhareddy Institute of Engineering \& Technology, Guntur, A.P., India

A Panduranga Rao, Assistant Professor in EEE department at Kallam Haranadhareddy Institute of Engineering \& Technology, Guntur, A.P., India

L Shanmukha Rao, Professor \& HOD of EEE at Kallam Haranadhareddy Institute of Engineering \& Technology, Guntur, A.P., India

(C) The Authors. Published by Blue Eyes Intelligence Engineering and Sciences Publication (BEIESP). This is an open access article under the CC BY-NC-ND license (http://creativecommons.org/licenses/by-nc-nd/4.0/)
Obviously, it is deteriorated from the voltage/current power quality (PQ) imperfections, which includes voltage and/or current harmonic distortions, reactive power mitigation, power factor improvement, voltage-sag, voltage swell, un-balancing loading. These PQ issues in multi-feeder distribution systems are not a new things but the awareness of these PQ issues has been increased at current situation by end-user consumers [2].

Traditional PQ compensation schemes like passive filters, static VAR capacitors, etc., have several demerits such as fixed compensation, massive, low dynamic response, resonance issues with source impedances, etc. An advanced Custom-Power (CP) apparatus based Active compensation methodology is used for improvement of above-specified PQ issues. The CP technology plays a significant role in power distribution system comprising of active power semiconductor technology to enhance the PQ features with a reliable operation and maintain the system as balanced way [3]. Several CP techniques use Voltage-Source Inverter (VSI) with an attractive control functions with the help of optimal reference voltage or current generation schemes. The unique dual-VSI based Unified Power Quality Compensator (UPQC) device is highly suitable for three phase distribution system, but it is un-feasible for multi-feeder system [4]. Alternatively, the choice is multi-feeder custom power apparatus can be integrated in between two adjacent lines for compensating current-voltage imperfections. The multi-feeder CP apparatus utilizes dual and/or more VSI's which are associated back-to-back formed as shunt-shunt, series-shunt and series-series modules. The merits of multi-feeder compensation devices are, enhances power-quality features occur in single and/or multi-feeders, another feeder provides energy to enhance the PQ concerns. Thus, the multi-feeder power-quality enhancement devices satisfy the unique performance over the single-feeder compensation devices. The multi-feeder UPQC (MF-UPQC) scheme furnishes the superior enhanced all voltage-current related PQ features in power distribution systems by using attractive control strategies. Various control strategies are used in MF-UPQC such as, Instantaneous PQ theory [5] is used for generation of reference current signal to shunt-VSI in Feeder-I and Synchronous Reference Frame (SRF) theory [6] is used for generation of reference voltage signal to series-VSI in Feeder-II with the help of common DC-link controller.

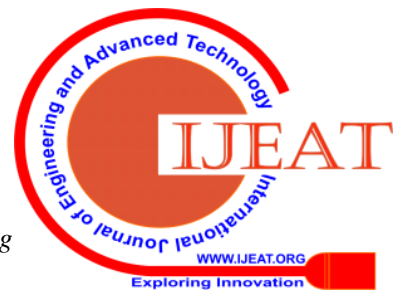


In general, DC-link controller utilizes the Proportional-Integral (PI) controller and the performance of controller depends on gain factors. The gain factors are initiated as trial and error process which is experienced based on control functions for acquiring the efficient performance to maintain DC-link voltage as constant. But, this classical PI and Fuzzy controller never regulates the DC-link voltage under sudden interruptions, parameter variations, moderate PQ compensation characteristics etc. This paper proposes novel Adaptive Neuro-Fuzzy Inference System (ANFIS) control function with good improved characteristics. It is constituted by emblematic path along with knowledge proficiency for prediction of optimal switching states to proposed MF-UPQC to acquire improved PQ features in a multi-feeder distribution system. The main intension of the ANFIS controller is to regulate the improved PQ features over the formal PI and fuzzy controllers. The performance of MF-UPQC is evaluated under the presence of classical PI, Fuzzy/Hybrid Fuzzy Logic and ANFIS controllers by using MATLAB/SIMULINK tool, simulation results conferred with comparative studies.

\section{PROPOSED MULTI-FEEDER UPQC DEVICE}

The schematic diagram of proposed MF-UPQC is shown in Fig.1, which consists of three-phase dual-VSI topologies as shunt-VSI and series-VSI integrated with a common DC-link capacitor. The source of dual feeder considered as $415 \mathrm{~V}$ driving the non-linear and sensitive loads in feeder-1 and feeder-2, respectively. The LC filter units are interfaced to minimize the switching ripples generated by VSI which is controlled by proposed ANFIS controller. The feeder- 1 is affected due to current harmonic distortions coming from non-linear load and feeder-2 which is affected due to LLL-G fault conditions, because these the PCC of multi-feeder distribution system is affected and attains poor PQ features. These PQ features are enhanced by initializing the MF-UPQC device with attractive control functions.

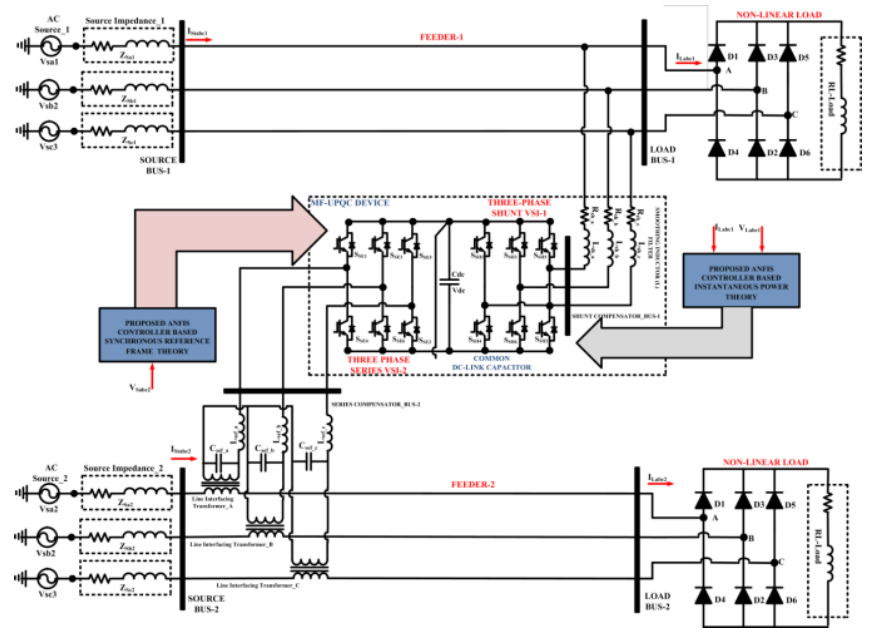

Fig.1 Schematic Diagram of Proposed MF-UPQC device with Proposed ANFIS Control Based Theory

\section{PROPOSED CONTROL FUNCTIONS}

The control scheme of proposed MF-UPQC device comprises of shunt-VSI and series-VSI compensator. An attractive and simple control algorithm was implemented to generate the reference current or reference voltage to achieve the optimal switching states to both shunt and series compensators. The control scheme of series-VSI utilizes SRF theory for generation of reference voltage signals, the SRF theory is commonly used in MF-UPQC device [7], [8]. The shunt-VSI of MF-UPQC utilized IRP theory for generation of reference current signal, control the real and reactive power and attains high dynamic response which effects the entire system.

\section{A.Control Scheme of Shunt-VSI Compensator}

The Instantaneous Real-Reactive power theory is very attractive control theory for generation of reference current signal with the controllability of real and reactive powers. The operating principle of IRP theory is generally situated based on transformation process of three-phase $a b c$ quantities to two quantities as $\alpha \beta$ sequences in a coordinated orthogonal frame. The input variables of IRP theory is load currents ( $\left.I_{\text {Labc }}\right)$ from sensors and source voltage $\left(V_{s a b c}\right)$ are fed to Park's transformation process [9]. This scheme provides the current-voltage component in coordinated orthogonal $\left(V_{\alpha \beta}, I_{\alpha \beta}\right)$ are used to represent the real and reactive powers. The instantaneous real \& reactive power sequences are measured based on above transformation process by specific equations as fundamental active current sequence and voltage functions $\left(V_{s \alpha \beta}, I_{L \alpha \beta}\right)$. The instantaneous vector coordinates are $V_{s a}, i_{L a}$ posed on the axis-"a" and respective magnitudes are changed with positive-negative with time. By using Park's transformation process these phases are transforming to $(\alpha-\beta)$ coordinates, follows as

$$
\begin{gathered}
{\left[\begin{array}{c}
v_{s \alpha} \\
v_{s \beta}
\end{array}\right]=\sqrt{\frac{2}{3}}\left[\begin{array}{ccc}
1 & \frac{-1}{2} & \frac{-1}{2} \\
0 & \frac{\sqrt{3}}{2} & \frac{-\sqrt{3}}{2}
\end{array}\right]\left[\begin{array}{c}
v_{s a} \\
v_{s b} \\
v_{s c}
\end{array}\right]} \\
{\left[\begin{array}{l}
i_{L \alpha} \\
i_{L \beta}
\end{array}\right]=\sqrt{\frac{2}{3}}\left[\begin{array}{ccc}
1 & \frac{-1}{2} & \frac{-1}{2} \\
0 & \frac{\sqrt{3}}{2} & \frac{-\sqrt{3}}{2}
\end{array}\right]\left[\begin{array}{l}
i_{s a} \\
i_{s b} \\
i_{s c}
\end{array}\right]}
\end{gathered}
$$

Where, the $(\alpha-\beta)$ are coordinated orthogonal sequences, the classical immediate power for system can be depicted as;

$$
p=v_{s \alpha} i_{L \alpha}+v_{s \beta} i_{L \beta}
$$

The formal active power equation is defined as;

$$
p=v_{s a} i_{s a}+v_{s b} i_{s b}+v_{s c} i_{s c}
$$

Relatively, the formal IRP theory is defined as;

$$
q=-v_{s \beta} i_{L \alpha}+v_{s \alpha} i_{L \beta}
$$

Although, the instantaneous real-reactive power is illustrated in matrix form as;

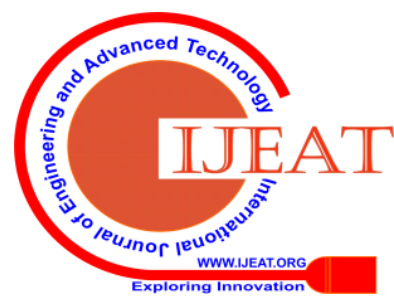




$$
\left[\begin{array}{c}
p \\
q
\end{array}\right]=\left[\begin{array}{cc}
v_{s a} & v_{s \beta} \\
-v_{s \beta} & v_{s a}
\end{array}\right]\left[\begin{array}{l}
i_{L \alpha} \\
i_{L \beta}
\end{array}\right]
$$

The $(\alpha-\beta)$ current components can be acquired as;

$$
\left[\begin{array}{c}
i_{L \alpha} \\
i_{L \beta}
\end{array}\right]=\frac{1}{\Delta_{k}}\left[\begin{array}{cc}
v_{s a} & v_{s \beta} \\
-v_{s \beta} & v_{s a}
\end{array}\right]\left[\begin{array}{l}
p \\
q
\end{array}\right]
$$

Where,

$$
\Delta_{k}=v_{s \alpha}^{2}+v_{s \beta}^{2}
$$

The active-current sequence is by-pass to High-Pass Filter (HPF) which is used to recognizing the harmonic elements from desired wave-shape. This filter eliminates the lower-order frequencies and allows high-order frequency into the system as reference current generation. The DC-link controller is used to regulate the common DC-link voltage of DCMLI-MCUPQC by utilizing ANFIS controller, which is used to control the DC-link voltage as maintained constant. The reference DC-link voltage $\left(V_{d c r}^{\bullet}\right)$ is directly compared to measured DC-link voltage $\left(V_{d c a}\right)$ and resembles the error quantities. The outcome error value from this task is fed to propose ANFIS controller for minimization of dominant error quantities in $P_{\text {Loss }}$ with good stability index. The instantaneous real $(p)$ and reactive power $(q)$ can be conveyed into a DC average and oscillatory components are,

$$
\begin{aligned}
& p=\bar{p}+p \\
& q=\bar{q}+q
\end{aligned}
$$

Where, $\bar{p}$ and $\bar{q}$ is DC average value $p$ and $q$ is AC oscillatory value of instantaneous real-reactive power theory. The reference compensator currents $i_{c \alpha}^{\bullet}$ and $i_{c \beta}^{\bullet}$ into $(\alpha-\beta)$ coordinates can be evaluated as

$$
\left[\begin{array}{c}
i_{c \alpha}^{\bullet} \\
i_{c \beta}^{\bullet}
\end{array}\right]=\frac{1}{\Delta_{k}}\left[\begin{array}{cc}
v_{a} & -v_{\beta} \\
v_{\beta} & v_{a}
\end{array}\right]\left[\begin{array}{l}
p \\
q
\end{array}\right]
$$

These reference currents are transformed to a-b-c components using Inverse transformation process as;

$$
\left[\begin{array}{c}
i_{c a}^{\bullet} \\
i_{c b}^{\bullet} \\
i_{c c}^{\bullet}
\end{array}\right]=\sqrt{\frac{2}{3}}\left[\begin{array}{ccc}
\frac{1}{\sqrt{2}} & 1 & 0 \\
\frac{1}{\sqrt{2}} & \frac{-1}{2} & \frac{\sqrt{3}}{2} \\
\frac{1}{\sqrt{2}} & \frac{1}{2} & \frac{-\sqrt{3}}{2}
\end{array}\right]\left[\begin{array}{c}
i_{0}^{\bullet} \\
i_{c \alpha}^{\bullet} \\
i_{c \beta}^{\bullet}
\end{array}\right]
$$

The evolution of reference current component in orthogonal coordinate $\left(i_{c a b c}^{\bullet}\right)$ is extracted by summation of active fundamental current component and ( $\left.\Delta_{i d}\right)$ component is called utmost reference current. The reference current $\left(i_{a b c}^{\bullet}\right)$ is differentiated to actual measured current from feeder-1 for producing optimal switching states to shunt-VSI compensator by Hysteresis Current Controller (HCC). The HCC is highly engaged to develop the optimal switching states to shunt VSI of MF-UPQC by using hysteresis band limits. This band limit acts as boundary conditions of compensation current which is controlled in between the upper and lower limits to generate the switching pulses to compensator. The switching pulses related to ON/OFF of switches in VSI are greatly depended by reference current and actual current component. When actual current is increased more than reference current then the respective switch is conducted and decreased the switch which is in OFF condition. However, the actual current is continuously swinging between inside the bands limits followed by reference current component provided by $\mathrm{I}_{\mathrm{d}}-\mathrm{I}_{q}$ synchronous detection scheme. The control objective of shunt-VSI of MF-UPQC device is depicted in Fig.2.

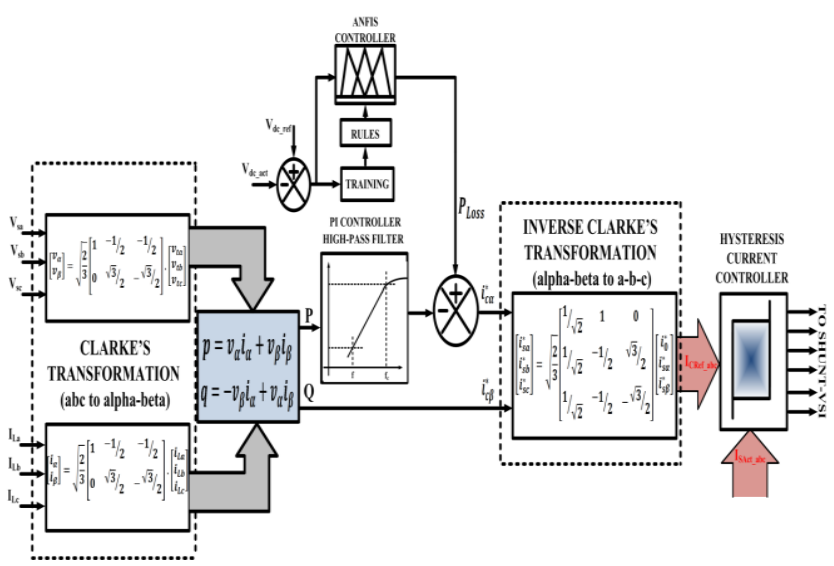

Fig.2 Schematic Diagram of Shunt-VSI Control Scheme of MF-UPQC Device

\section{B. Control Scheme of Series-VSI Compensator}

A well-recognized control scheme is best selection for superior performance of series-VSI compensator of MF-UPQC. The main intension of series-VSI controller is to maintain the constant voltage magnitude at Feeder-1 and Feeder-2 under voltage-imperfections. The working of series-VSI of MF-UPQC is greatly depends on analogy of appropriate load voltage with respect to actual line voltage [10]. The attained error quantities are resolved dynamically by differentiating the actual and reference voltage values. The Phase-Locked Loop (PLL) is used to generate the unit-sinusoidal functions which are in-phase with main utility-grid voltage. The actual voltage measured from load-bus of Feeder-2 $\left(V_{L a b c}\right)$ are transformed into $d q$ quantities as $V_{d q 0 a c t}$ by using Clarke's transformation process.

$\left[\begin{array}{c}V_{\text {dact }} \\ V_{\text {qact }} \\ V_{0}\end{array}\right]=\frac{2}{3}\left[\begin{array}{ccc}\cos \theta & \cos \left[\theta-\frac{2 \pi}{3}\right] & \cos \left[\theta+\frac{2 \pi}{3}\right] \\ \sin \theta & \sin \left[\theta-\frac{2 \pi}{3}\right] & \sin \left[\theta+\frac{2 \pi}{3}\right] \\ \frac{1}{2} & \frac{1}{2} & \frac{1}{2}\end{array}\right]\left[\begin{array}{c}V_{L a} \\ V_{L b} \\ V_{L c}\end{array}\right]$

The " $\omega$ " angular velocity and $\theta$ is the displacement factor which is associated by

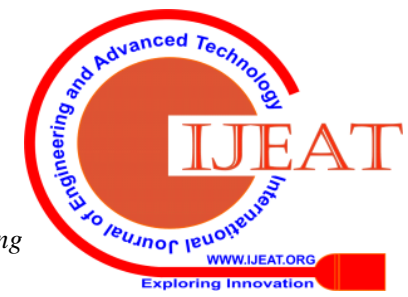




$$
\theta=\int \omega d t
$$

The control scheme of series-VSI of MF-UPQC encounters the $a b c$ to $d q$ transformation of reference and actual voltages. During the normal and symmetrical situations, the voltage is sustained constant and the $d$-frame voltage is retained as unity (p.u) and $q$-frame voltage which set as zero (0 p.u). After the transormation process, the outcome voltage like ( $V_{\text {dqact }}$ ) is compared to reference voltages ( $\left.V_{\text {dqref }}\right)$. When both the actual and reference voltage vectors are compared and attain some error quantities. These error quantities are minimized by using proposed ANFIS controller.

Ultimately, the error is counteracted and the outcome values treated as reference voltage generation in $d$ - $q$ frame is $\left(V_{d q}^{\bullet}\right)$.

The reference voltage values in $d$-q frame is re-transformed to $a b c$ frame by using inverse-transformation process as shown in Equation (15).

$$
\begin{gathered}
V_{d q}^{\cdot}=V_{\text {dqref }}-V_{\text {dqact }} \\
{\left[\begin{array}{c}
V_{\text {aref }} \\
V_{\text {bref }} \\
V_{\text {cref }}
\end{array}\right]=\frac{2}{3}\left[\begin{array}{ccc}
\cos \theta & \sin \theta & 1 \\
\cos \left[\theta-\frac{2 \pi}{3}\right] & \sin \left[\theta-\frac{2 \pi}{3}\right] & 1 \\
\cos \left[\theta+\frac{2 \pi}{3}\right] & \sin \left[\theta+\frac{2 \pi}{3}\right] & 1
\end{array}\right]\left[\begin{array}{c}
V_{d}^{\bullet} \\
V_{q}^{\bullet}
\end{array}\right]}
\end{gathered}
$$

The reference voltage in $a b c$ frame is $V_{a b c r e f}$ is used as reference voltage signal to generate optimal switching states by using sinusoidal PWM scheme. The schematic diagram of series-VSI control scheme of MF-UPQC is shown in Fig.3.

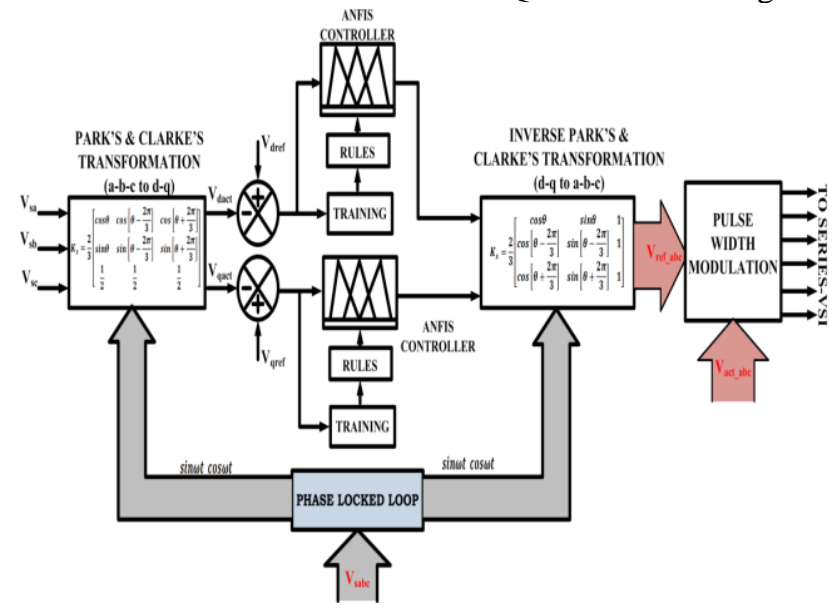

Fig.3 Schematic Diagram of Series-VSI Control Scheme of MF-UPQC Device

\section{C.Proposed ANFIS Controller}

Several artificial intelligent control schemes are highly used in several applications, In that ANFIS controller has been greatly recognized due to enhanced performance over the classical PI and Fuzzy controllers [11], [12]. The eminent characteristics of intelligent controller is that they comprising as symbolic notation of inference system along with expertise knowledge. It is more requisite for optimal performance of MF-UPQC; the best suitable controller for this application is
ANFIS which is predominantly enhances the PQ features. It is the unique integral approach for respective task and yields the outcome switching sequences to the VSI of MF-UPQC. In ANFIS, the knowledge system is acquired from supervised learning algorithm by utilizing the hybrid method or back-propagation algorithm [13]. It can improve the over-all system performance in many ways such as good stability index, better reduction of THDs, smooth operation, more reliability, etc. It has incredible ability to attain a supported group as an optimal membership functions are highly used for clustering and deducting the acquired outcome within nominal epochs. The principle of ANFIS structure at initial state is; system provides the test data fuzzy rules which are transformed to attractive training methodology for generation of optimum membership functions and rules. It any violations

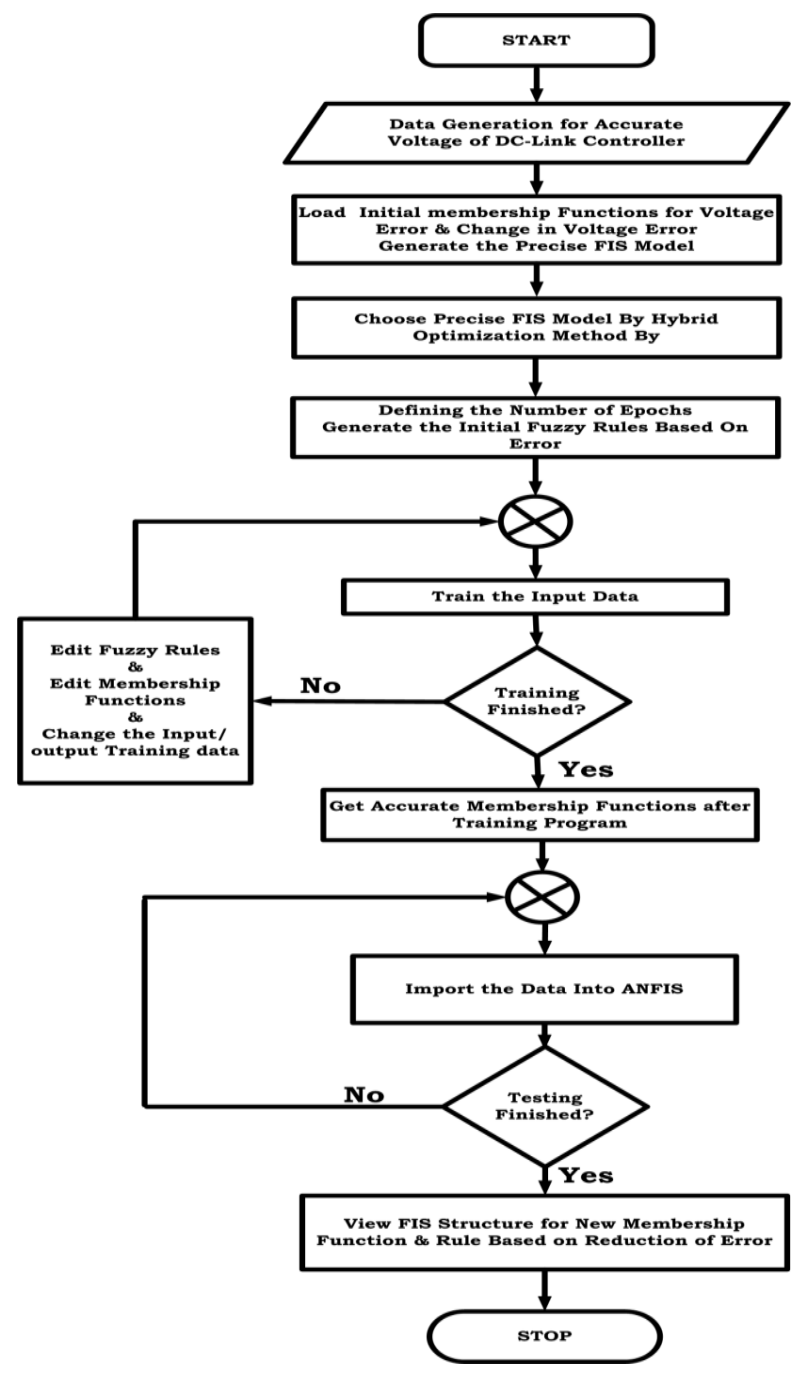

occurs or doesn't reach Fig.5. Flowchart of ANFIS Controller

the predefined error value, the second process is initiated. It is nothing but, based on provided rules/membership functions, ANFIS generates the new FIS configuration with respect to system error and change in error quantities. The membership functions for error $(E)$ and change in error (CE) are depicted in Figure.4.

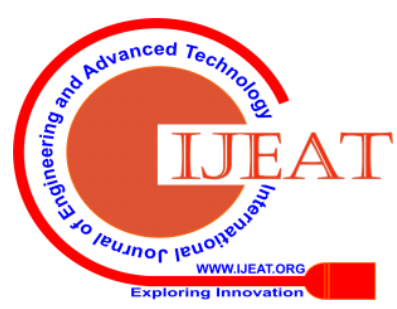




$$
\begin{aligned}
& e(S)=\omega_{r}^{*}-\omega_{\text {act }} \\
& \Delta e(S)=e(S)-e(S-1)
\end{aligned}
$$

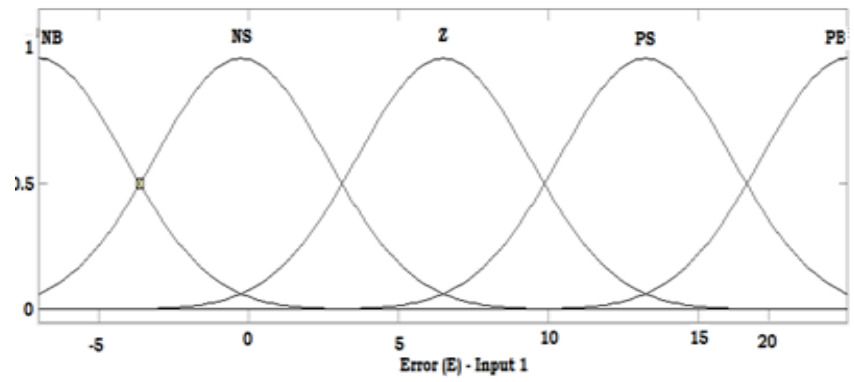

(a) Error e(s)

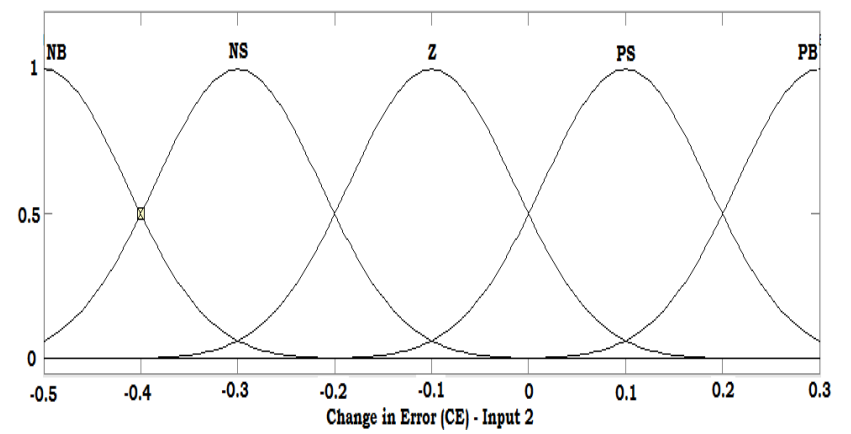

(b) Change in Error $\Delta e(S)$

Figure.4. Membership Functions

Several membership functions are EZ-Zero Error; PS-Positive Small; PB-Positive Big and NS-Negative Small and NB-Negative Big value respectively. Several rules of the ANFIS structure are illustrated as below in Table.1. The flowchart of the ANFIS Controller is illustrated in Figure.5.

TABLE.1. RULES FOR ANFIS STRUCTURE
\begin{tabular}{|c|c|c|c|c|c|}
\hline$e(S) / \Delta e(S)$ & NB & NS & EZ & PS & PB \\
\hline NB & R1 & R 2 & R 3 & R 4 & R 5 \\
\hline NS & R 6 & R 7 & R 8 & R 9 & R 10 \\
\hline Z & R 11 & R 12 & R 13 & R 14 & R 15 \\
\hline PS & R 16 & R 17 & R 18 & R 19 & R 20 \\
\hline PB & R 21 & R 22 & R 23 & R 24 & R 25 \\
\hline
\end{tabular}

\section{MATLAB/SIMULINK RESULTS}

The performance of proposed MF-UPQC is verified under various control functions by using MATLAB/SIMULINK tool with operating specifications as depicted in Table.2.

Table.2 Operational Parameters of Proposed MF-UPQC

\begin{tabular}{|c|c|c|}
\hline S. No & $\begin{array}{l}\text { Several Operational } \\
\text { Parameters }\end{array}$ & Values \\
\hline 1 & $\begin{array}{c}\text { Feeder-1 and } \\
\text { Feeder-2 Source Voltage }\end{array}$ & $415 \mathrm{~V}, 50 \mathrm{~Hz}$, \\
\hline 2 & Source Impedance & $\mathrm{R}_{\mathrm{s}}=0.15 \Omega, \mathrm{L}_{\mathrm{s}}-0.9 \mathrm{mH}$ \\
\hline 3 & Load Impedance & $R_{L}=30 \Omega, L_{L}-20 \mathrm{mH}$ \\
\hline 4 & $\begin{array}{r}\text { Line Interfacing } \\
\text { Transformer (1:1) }\end{array}$ & $\begin{array}{l}\text { 415V, 50Hz, 5KVA, Linear } \\
\text { Model, } 10 \% \text { Leakage Reactance }\end{array}$ \\
\hline 5 & $\begin{array}{l}\text { Series-VSI Filter } \\
\text { Module }\end{array}$ & $\mathrm{L}_{\mathrm{se}}-3 \mathrm{mH}, \mathrm{C}_{\mathrm{se}}-100 \mu \mathrm{F}$ \\
\hline 6 & $\begin{array}{l}\text { Shunt-VSI Filter } \\
\text { Module }\end{array}$ & $R_{\mathrm{sh}}=0.001 \Omega, L_{\mathrm{sh}}-10 \mathrm{mH}$ \\
\hline 7 & $\begin{array}{l}\text { DC Link Source } \\
\text { (Capacitor) }\end{array}$ & $V_{d c}=880 \mathrm{~V}, C_{d c}=1500 \mu F$ \\
\hline
\end{tabular}
System in Multi-Feeder Distribution System

Case A: Performance of Proposed MF-UPQC device under Classical PI Controller


$$
\text { SHUNT COMPEHSATOR CURRERT }
$$
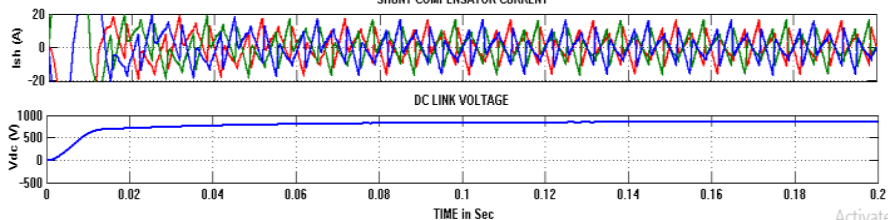

(a) Shunt-VSI of MF-UPQC in Feeder-1 System

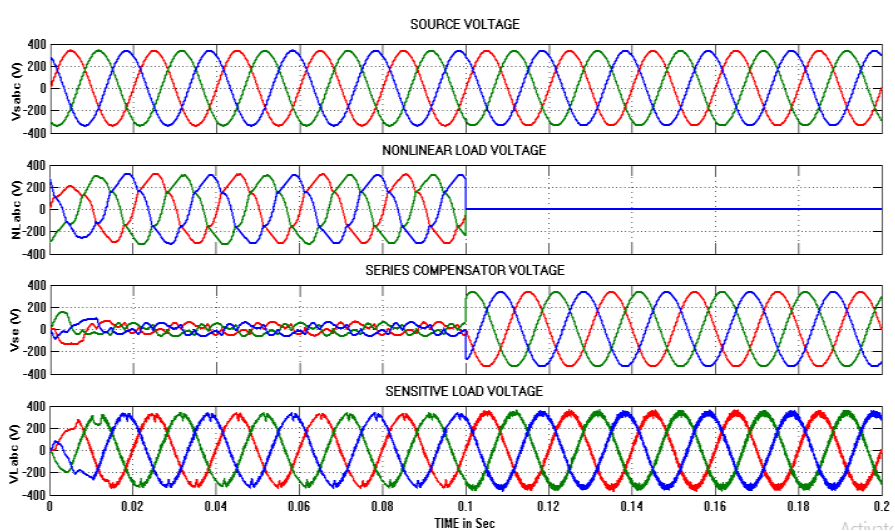

(b) Series-VSI of MF-UPQC in Feeder-2 System

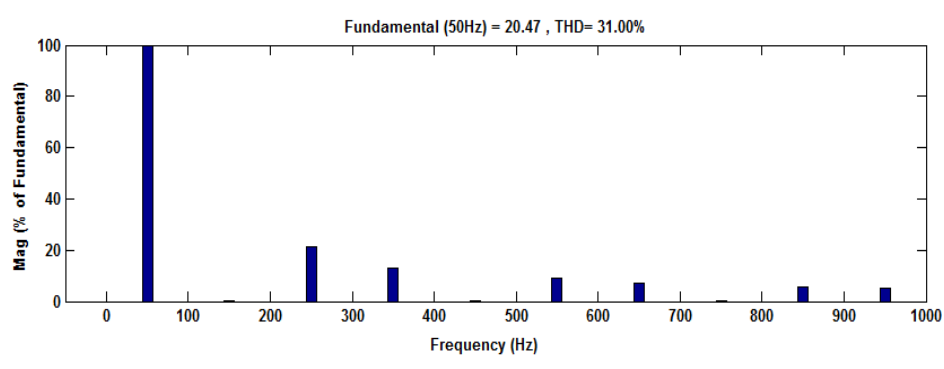

(c) THD of Source Current without Shunt Compensator

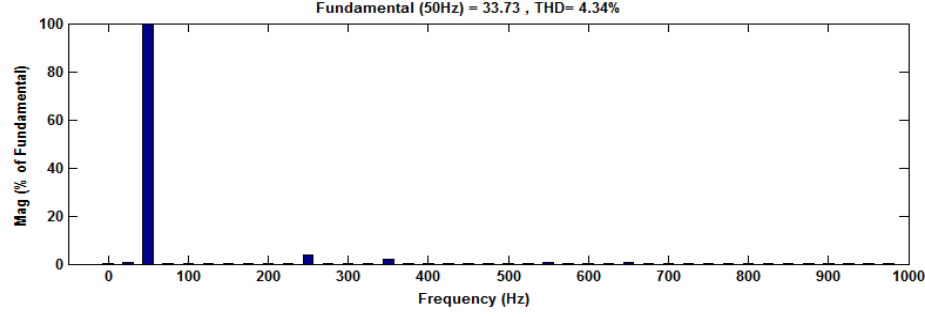

(d) THD of Source Current

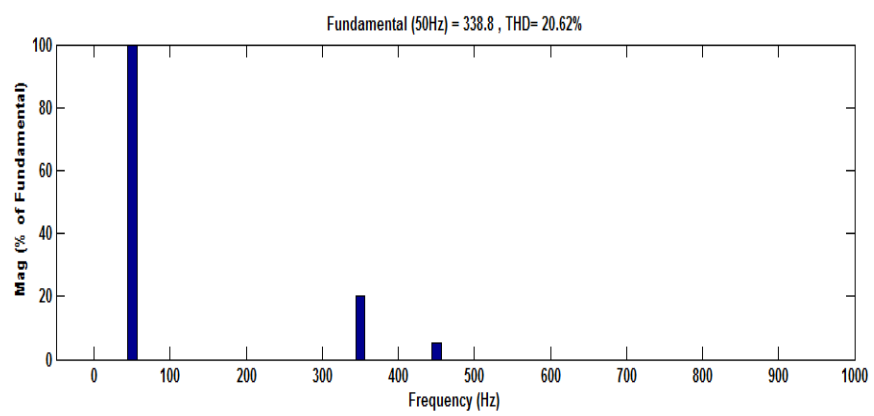

(e) THD of Load Voltage without Series Compensator

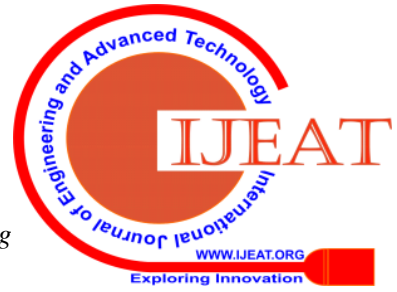




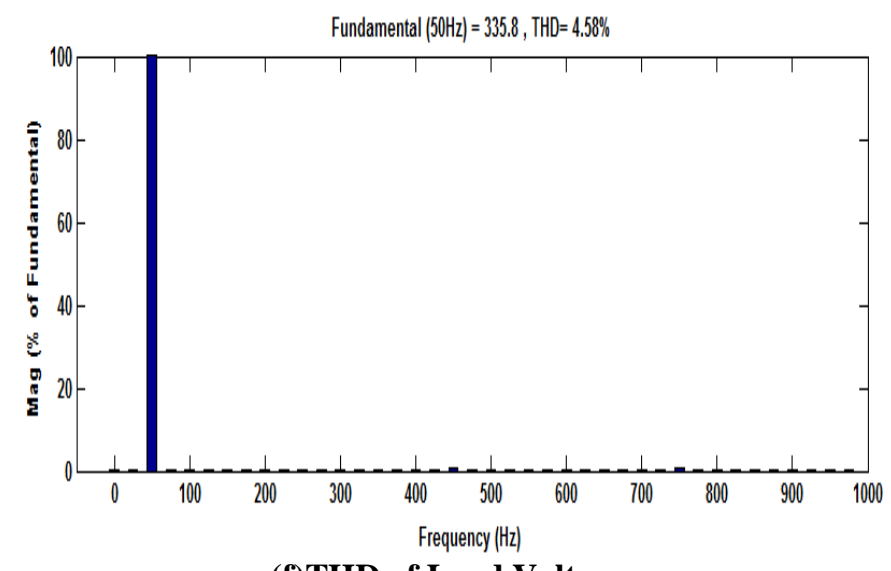

(f)THD of Load Voltage

Fig.6 Simulation Results of Proposed MF-UPQC under Classical PI Controller in Multi-Feeder Distribution System

The performance of proposed MF-UPQC under classical PI controller in Multi-Feeder distribution system is shown in Fig.6. In that, Fig. 6(a) represents the shunt-VSI characteristics, the source voltage, source current, load current, compensation current and DC-link voltage are the key parameters. The shunt-VSI acts as controlled current-source to compensate current harmonics coming from non-linear load and maintain PCC current as balanced and sinusoidal nature and the DC-link voltage maintained as constant. Fig. 6(b) represents the series-VSI characteristics, the source voltage, non-linear load voltage, sensitive load voltage and compensator voltage which are the key parameters. The series-VSI acts as controlled voltage-source and injects pre-requisite voltage to compensate voltage-sag due to LLL-G fault and load voltage as balanced and maintained as constant. The Total Harmonic Distortions (THD) of source current without shunt compensator is $31.00 \%$ as depicted in Fig.6 (c) and the THD of source current with shunt-VSI is $4.34 \%$ as depicted in Fig.6 (d) and the THD of load voltage without series compensator is $20.62 \%$ as depicted in Fig.6 (d) with series-VSI is $4.58 \%$ as depicted in Fig.6 (e).

Case B: Performance of Proposed MF-UPQC device under Proposed Fuzzy-Logic Controller

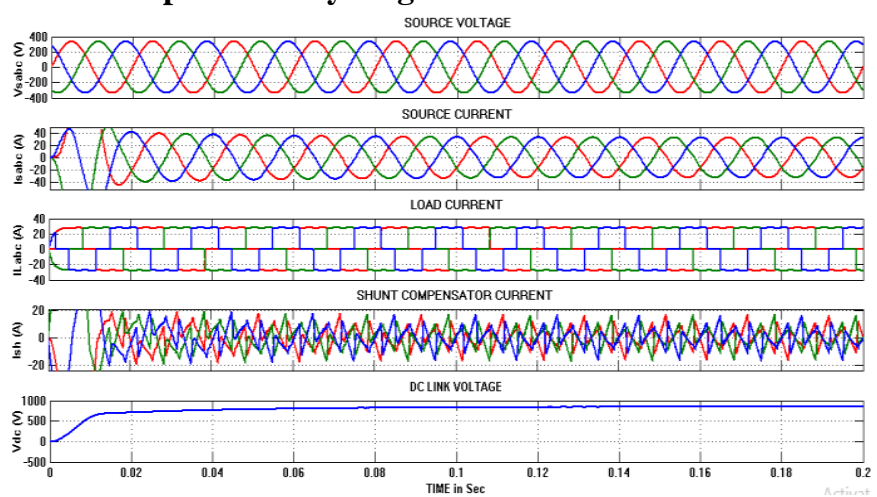

(a) Shunt-VSI of MF-UPQC in Feeder-1 System

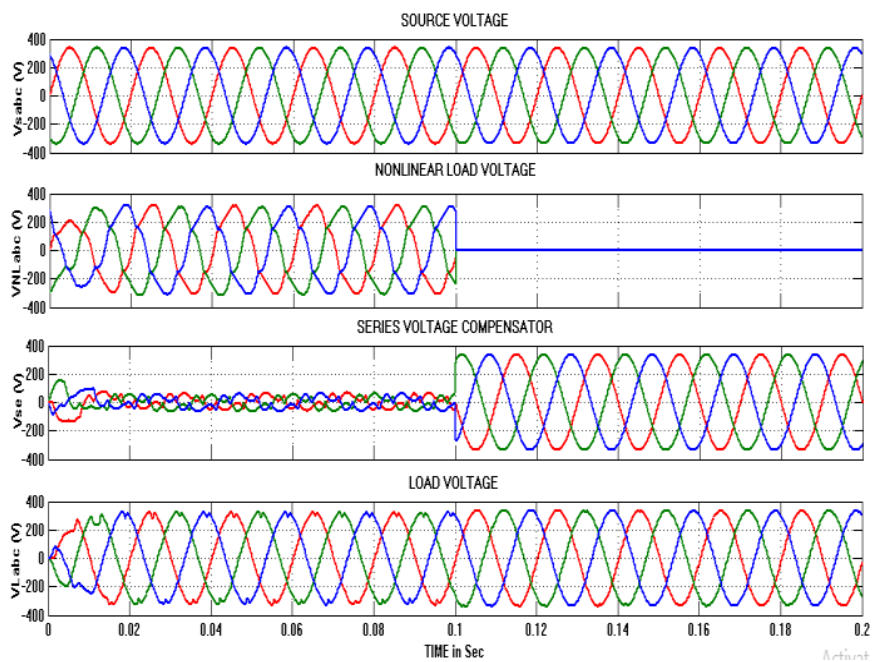

(b) Series-VSI of MF-UPQC in Feeder-2 System Fundamental $(50 \mathrm{~Hz})=33.34, \mathrm{THD}=2.11 \%$

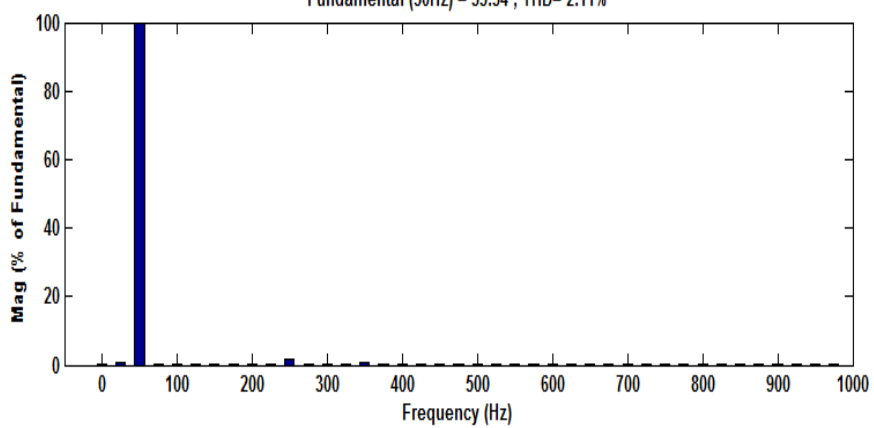

(c) THD of Source Current

Fundamental $\mid(5 \mathrm{~Hz} \mid=336.1, \mathrm{THD}=1.21 \%$

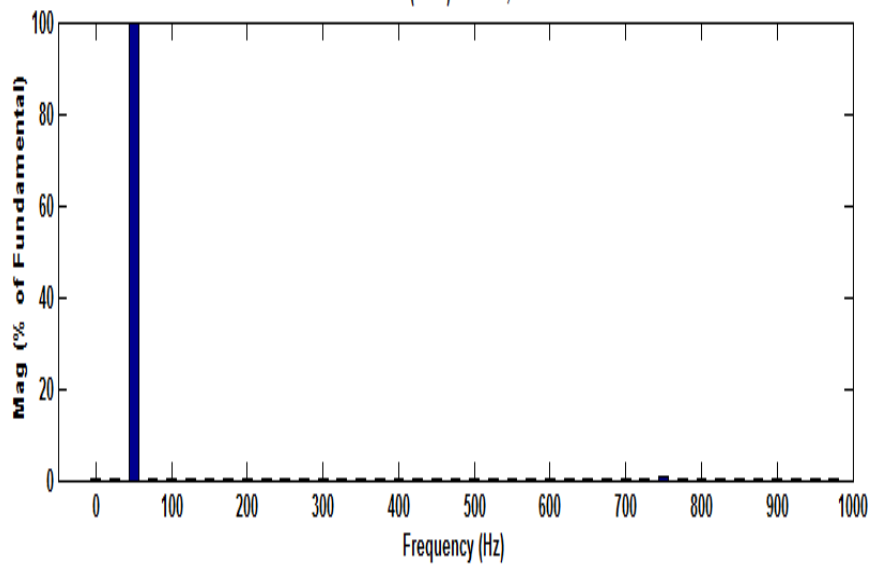

(d) THD of Load Voltage

Fig.7 Simulation Results of Proposed MF-UPQC under Proposed Fuzzy-Logic Controller in Multi-Feeder Distribution System

The performance of proposed MF-UPQC under Proposed Fuzzy-Logic controller in Multi-Feeder distribution system is shown in Fig.7. In that, Fig. 7(a) represents the improved shunt-VSI characteristics over the classical PI controller, the source voltage, source current, load current, compensation current and DC-link voltage which are the key parameters. The shunt-VSI acts as controlled current-source to compensate current harmonics coming from non-linear load and maintain PCC current as balanced and sinusoidal nature with enhanced PQ features and the DC-link voltage maintained as constant.

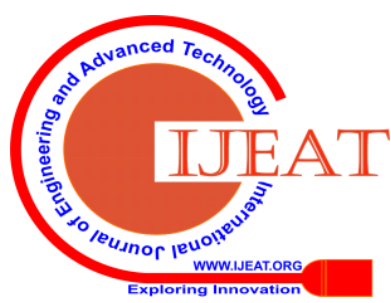


Fig. 7(b) represents the series-VSI characteristics over the classical PI controller, the source voltage, non-linear load voltage, sensitive load voltage, compensator voltage are the key parameters. The series-VSI acts as controlled voltage-source and injects pre-requisite voltage to compensate voltage-sag due to LLL-G fault and load voltage as balanced and maintained as constant. The Total Harmonic Distortions (THD) of source current with shunt-VSI is $2.11 \%$ as depicted in Fig.7 (c) and the THD of load voltage with series-VSI is $1.21 \%$ as depicted in Fig.7 (d). The obtained THD values are within IEEE-519 standard limitations.

Case C: Performance of Proposed MF-UPQC device under Hybrid Fuzzy-Logic Controller

SOURCE VOLTAGE

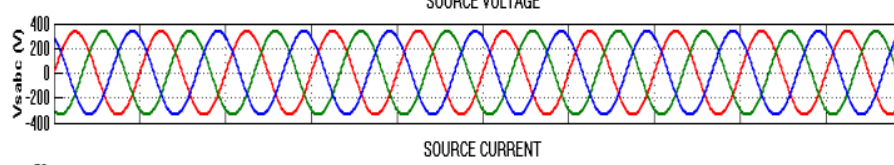

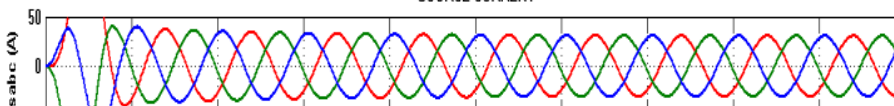
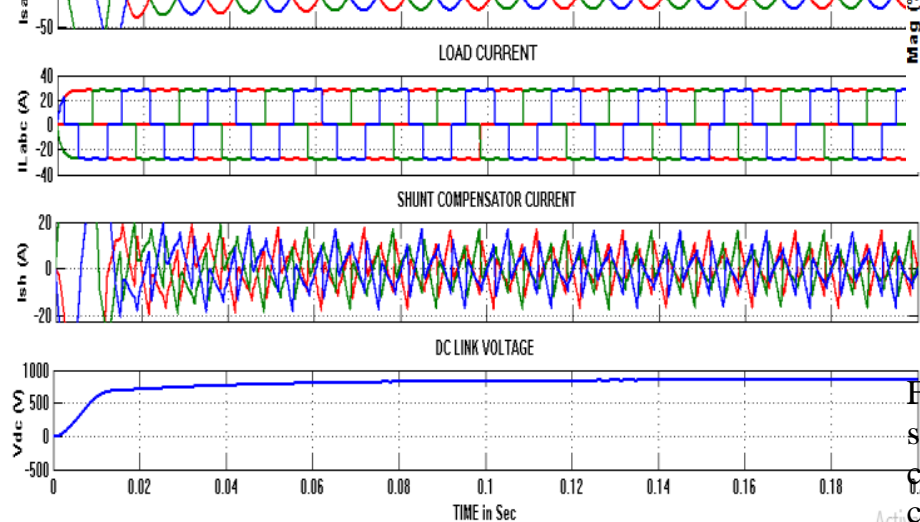

(a) Shunt-VSI of MF-UPQC in Feeder-1 System SOURCEVOLTAGE
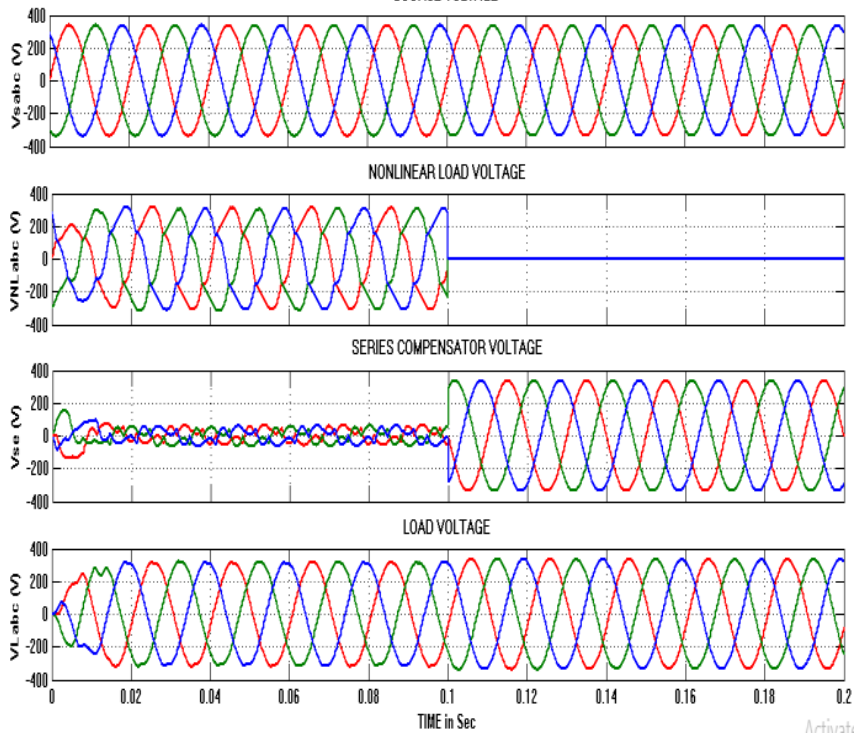

(b) Series-VSI of MF-UPQC in Feeder-2 System

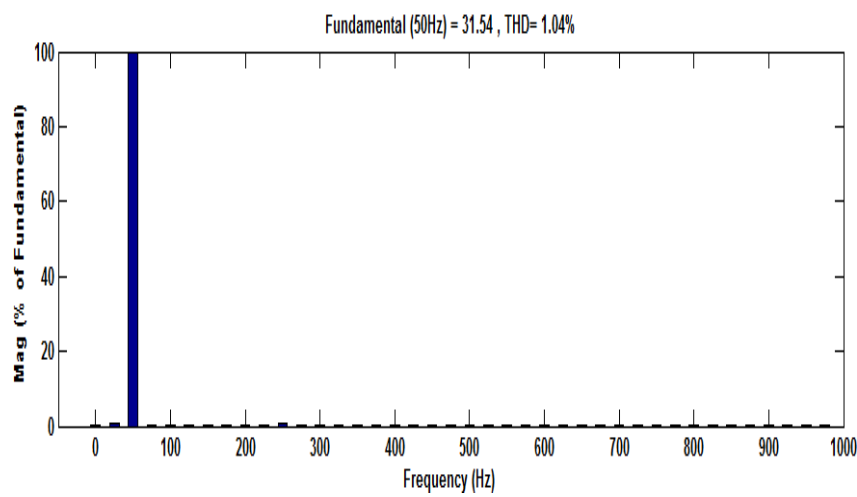

(c) THD of Source Current

Fundamental $\mid 50 \mathrm{~Hz})=335.9, \mathrm{THD}=0.69 \%$

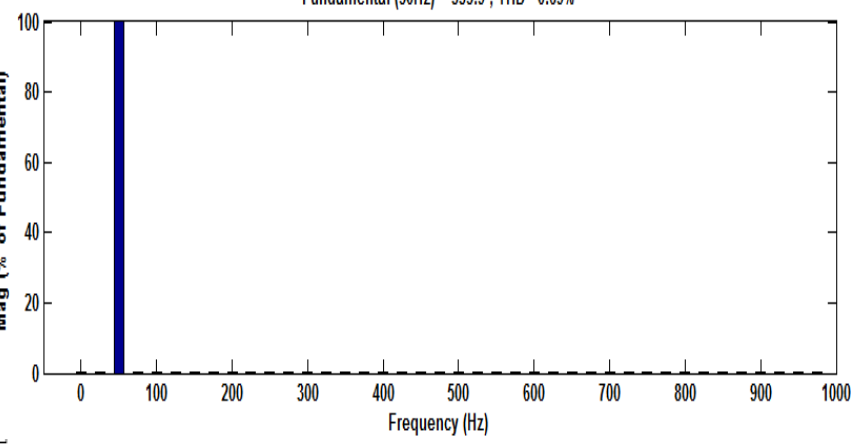

(d) THD of Load Voltage

Fig.8 Simulation Results of Proposed MF-UPQC under Hybrid Fuzzy-Logic Controller in Multi-Feeder Distribution System

The performance of proposed MF-UPQC under Hybrid Fuzzy-Logic controller in Multi-Feeder distribution system is shown in Fig.8. Fig. 8(a) represents the improved shunt-VSI fharacteristics over the classical PI and Fuzzy-Logic controller, the source voltage, source current, load current, compensation current and DC-link voltage are the key parameters. The shunt-VSI acts as controlled current-source to compensate current harmonics coming from non-linear load and maintain PCC current as balanced and sinusoidal nature with enhanced PQ features and the DC-link voltage maintained as constant. Fig.8(b) represents the series-VSI characteristics over the classical PI and Fuzzy-Logic controller, the source voltage, non-linear load voltage, sensitive load voltage, compensator voltage are the key parameters. The series-VSI acts as controlled voltage-source and injects pre-requisite voltage to compensate voltage-sag due to LLL-G fault and load voltage as balanced and maintained as constant. The Total Harmonic Distortions (THD) of source current with shunt-VSI is $1.04 \%$ as depicted in Fig.8 (c) and the THD of load voltage with series-VSI is $0.69 \%$ as depicted in Fig.8 (d). The obtained THD values are well within IEEE-519 standard limitations and attain enhanced PQ features over the classical control functions. 
Case D: Performance of Proposed MF-UPQC device under Proposed ANFIS Controller
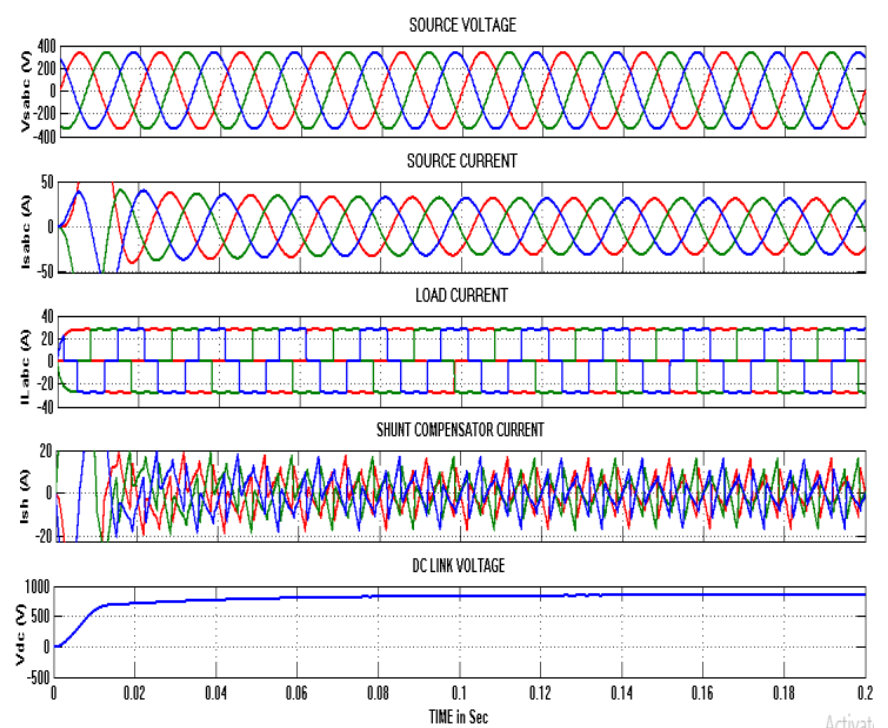

(a) Shunt-VSI of MF-UPQC in Feeder-1 System SOURCE VOLTAGE
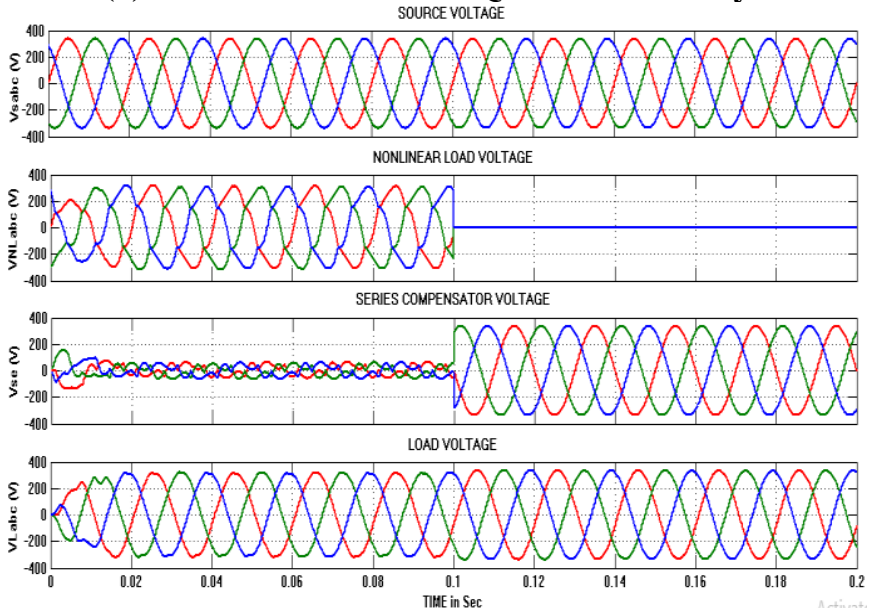

(b) Series-VSI of MF-UPQC in Feeder-2 System

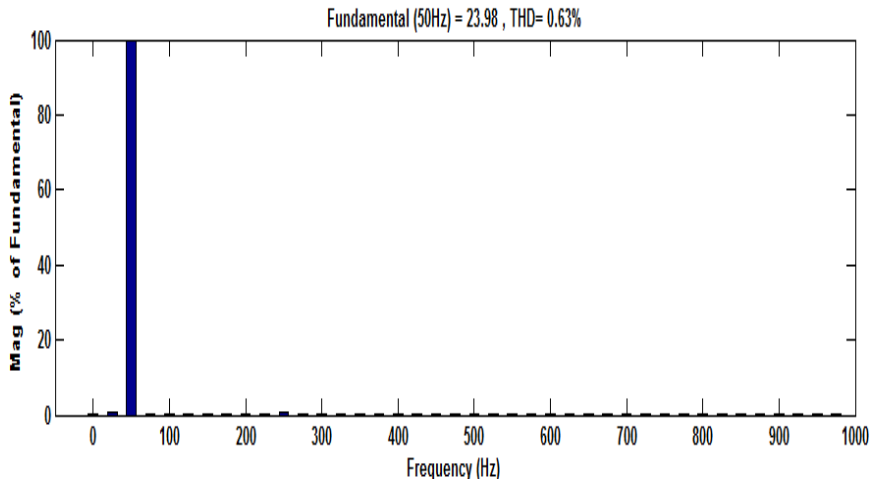

(c) THD of Source Current

Fundamental $(5 \mathrm{OHz})=325.7, \mathrm{THD}=0.48 \%$

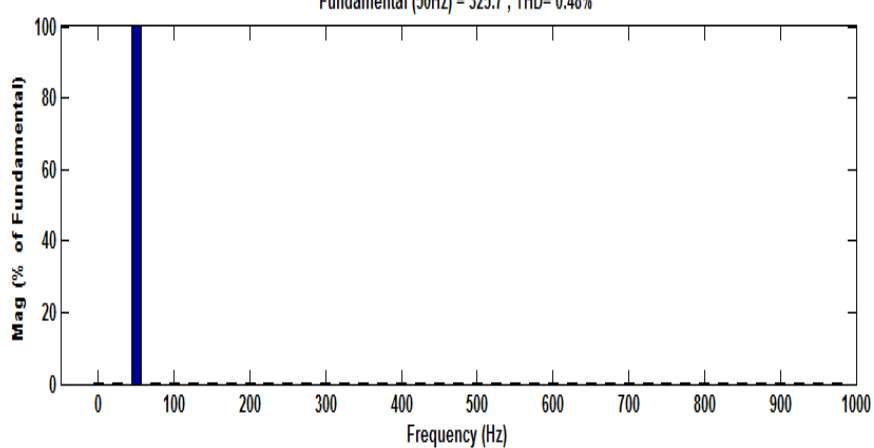

(d) THD of Load Voltage
Fig.9 Simulation Results of Proposed MF-UPQC under Proposed ANFIS Controller in Multi-Feeder Distribution System

The performance of proposed MF-UPQC under Proposed ANFIS controller in Multi-Feeder distribution system is shown in Fig.9. In that, Fig. 9(a) represents the improved shunt-VSI characteristics over the classical PI, Fuzzy and Hybrid-Fuzzy Logic controller, the source voltage, source current, load current, compensation current and DC-link voltage which are the key parameters. The shunt-VSI acts as controlled current-source to compensate current harmonics coming from non-linear load and maintain PCC current as balanced and sinusoidal nature with enhanced PQ features and the DC-link voltage maintained as constant. Fig.9(b) represents the series-VSI characteristics classical PI, Fuzzy and Hybrid-Fuzzy Logic controller, the source voltage, non-linear load voltage, sensitive load voltage and compensator voltage which are the key parameters. The series-VSI acts as controlled voltage-source and injects pre-requisite voltage to compensate voltage-sag due to LLL-G fault and load voltage as balanced and maintained as constant. The Total Harmonic Distortions (THD) of source current with shunt-VSI is $0.63 \%$ as depicted in Fig.9 (c) and the THD of load voltage with series-VSI is $0.48 \%$ as depicted in Fig.9(d). The obtained THD values are well within IEEE-519 standard limitations and attain enhanced PQ features over the classical control functions. Over the classical PI, Fuzzy and Hybrid-Fuzzy Logic controller, the proposed ANFIS controller has better reduction of source current and load voltage distortions. The THDs of both parameters are well within IEEE standard limitations for attaining improved PQ features in a multi-feeder distribution system as depicted in Table. 3 and the graphical view is depicted in Fig.10.

Table.3 THD Comparison of Source Current and Load Voltage under Several Control Functions

\begin{tabular}{|c|c|c|c|c|c|}
\hline $\begin{array}{c}\text { THD } \\
(\%)\end{array}$ & $\begin{array}{c}\text { With } \\
\text { out } \\
\text { Compen } \\
\text { sator }\end{array}$ & $\begin{array}{c}\text { Classical } \\
\text { PI } \\
\text { Controll } \\
\text { er }\end{array}$ & $\begin{array}{c}\text { Classica } \\
\text { I } \\
\text { Fuzzy } \\
\text { Logic } \\
\text { Controll } \\
\text { er }\end{array}$ & $\begin{array}{c}\text { Classical } \\
\text { Hybrid } \\
\text { Fuzzy } \\
\text { Logic } \\
\text { Controller }\end{array}$ & $\begin{array}{c}\text { Propose } \\
\text { d } \\
\text { ANFIS } \\
\text { Controll } \\
\text { er }\end{array}$ \\
\hline $\begin{array}{c}\text { Source } \\
\text { Curre } \\
\text { nt }\end{array}$ & $31.00 \%$ & $4.34 \%$ & $2.11 \%$ & $1.04 \%$ & $0.63 \%$ \\
\hline $\begin{array}{c}\text { Load } \\
\text { Voltag } \\
\text { e }\end{array}$ & $20.62 \%$ & $4.58 \%$ & $1.21 \%$ & $0.69 \%$ & $0.48 \%$ \\
\hline
\end{tabular}

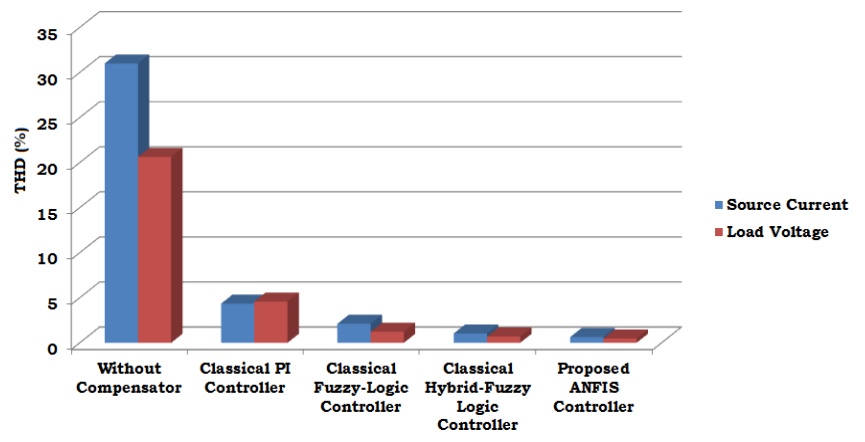

Fig.9 Graphical View of THD Analysis under Various Control Functions

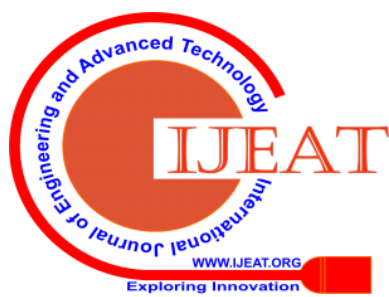




\section{CONCLUSION}

The performance of proposed MF-UPQC is verified under non-linear loads and LLLG-fault conditions; the proposed dual compensation technology. It is effectively used to compensate the all current-voltage related $\mathrm{PQ}$ issues in multi-feeder distribution. The proposed MF-UPQC is evaluated by using MATLAB/SIMULINK tool under various control functions for attaining improved PQ features. Over the classical PI controller, Fuzzy-Logic controller, and Hybrid Fuzzy-Logic controller, the proposed ANFIS controller has good compensation characteristics and the THD values are well within IEEE-519 standards.

From above discussions the MF-UPQC with proposed ANFIS controller furnishes best performance for all voltage-current imperfections.

\section{REFERENCES}

1. J. H. Eto, K. H. LaCommare, "A quantitative assessment of utility reporting practices for reporting electric power distribution events", Proc. 2012 IEEE Power \& Energy Soc. General Meeting, Jul. 22-26, 2012.

2. S. P. Jolhe, M. D. Karalkar, G. A. Dhomane, "Smart grid and power quality (PQ) issues" 2016 Online IEEE International Conference on Green Engineering and Technologies (IC-GET), 2016.

3. Ghosh, A. and Ledwich, G, "Power Quality Enhancement Using Custom Power Devices," Kulwer International Series in Engineering and Computer Science, vol.3, no.15, pp. 75-81,2002.

4. B. W. Frana, L. F. da Silva, M. A. Aredes and M. Aredes, "An Improved IUPQC Controller to Provide Additional Grid-Voltage Regulation as a STATCOM," in IEEE Transactions on Industrial Electronics, vol. 62, no. 3, pp. 1345-1352, March 2015.

5. K. Palanisamy, J. S. Mishra, I. J. Raglend, D. P. Kothari, "Instantaneous power theory based unified power quality conditioner (UPQC)", Proc. Int. Conf. Power Electron. Drives Energy Syst., pp. 1-5, 2010-Dec

6. P. Vasudeva Naidu, B. Basavaraja, "Design of a SRF based MC UPQC used for load voltage control in Parallel distribution systems", Power India Conference 2012 IEEE Fifth, pp. 1-6, 2012

7. M.A.A. Yahiya and M.A.R Uzair, "Performance analysis of DVR, DSTATCOM and UPQC for improving the power quality with various control strategies" International Conference on Power and Energy Systems: Towards Sustainable Energy (PESTSE), July 2016, pp1-4.

8. G. Satyanarayana, K. Lakshmi Ganesh, C. Narendra Kumar, M. Vijaya Krishna, "A critical evaluation of power quality features using Hybrid Multi-Filter Conditioner topology", Green Computing Communication and Conservation of Energy (ICGCE) 2013 International Conference on, pp. 731-736, 2013.

9. S. S. Pawar, A. Deshpande, and M. Murali, "Modelling and simulation of DSTATCOM for power quality improvement in distribution system using MATLAB Simulink tool," in Energy Systems and Applications, 2015 International Conference on, pp. 224-227, IEEE, 2015.

10.Babu, P. Sathish, and N. Kamaraj. "Performance investigation of dynamic voltage restorer using PI and fuzzy controller," IEEE Power, Energy and Control(ICPEC), 2013 International Conference on,2013

11.G. Satyanarayana, K.N.V. Prasad, G. Ranjith Kumar, K. Lakshmi Ganesh, "Improvement of power quality by using hybrid fuzzy controlled based IPQC at various load conditions", Energy Efficient Technologies for Sustainability (ICEETS) 2013 International Conference on, pp. 1243-1250, 2013.

12.G. Satyanarayana, K. Lakshmi Ganesh "Tuning a Robust Performance of Adaptive Fuzzy-PI Driven DSTATCOM for Non-Linear Process Applications" is Published in Springer LNCS Series-8947, ISSN-0302-9743, pp.523-533, July 2015

13.M. Singh and A. Chandra, "Real-time implementation of ANFIS control for renewable interfacing inverter in 3P4W distribution network", IEEE Trans. Ind. Electron., vol. 60, no. 1, pp. 121-128, 2013.

14.S S N L Bhavani and L.Shanmukha Rao.,"Realization of Novel Multi-Feeder UPQC for Power Quality Enhancement Using Proposed Hybrid Fuzzy+PI Controller" IEEE International conference on Innovations in Power and Advanced Computing Technologies (i-PACT - 2019)VIT,Vellore,India,2019.

15.A CRITICAL EVALUATION OF PV+WIND CO-GENERATION SCHEME

16.BASED STATIC COMPENSATOR FOR PQ IMPROVEMENT BY USING
17.FUZZY-LOGIC CONTROLLER

18.A CRITICAL EVALUATION OF PV+WIND CO-GENERATION SCHEME

19.BASED STATIC COMPENSATOR FOR PQ IMPROVEMENT BY USING

20.FUZZY-LOGIC CONTROLLER

21.A CRITICAL EVALUATION OF PV+WIND CO-GENERATION SCHEME

22.BASED STATIC COMPENSATOR FOR PQ IMPROVEMENT BY USING

23.FUZZY-LOGIC CONTROLLER

24. J Pavithra and L.Shanmukha Rao, "A Critical Evaluation of PV+Wind Co-Generation Scheme Based Static Compensator For PQ Improvement By Using Fuzzy-Logic Controller" IEEE International conference on Innovations in Power and Advanced Computing Technologies (i-PACT - 2019)VIT,Vellore,India,2019.

25.Sk.Shabana, L.Shanmukha Rao, "Interconnection of Hybrid Power System to Grid \& Enhance Power Quality Features in DG System Using Multilevel STATCOM International Journal of Engineering and Advanced Technology, Volume-9, Issue-3,Febraury 2020.

26.J Vara Lakshmi, L,Shanmukha Rao, "Power Quality Improvement Using Intelligent Fuzzy-VLLMS Based Shunt Active Filter", International Journal of Recent Technology and Engineering, Volume-8, Issue-6, March 2020.

27.T Ganesh, L.Shanmukha Rao,"Performance Assesment of Plug-in Electric Vehicle Supported DVR for Power-Quality Improvement and Energy Back-Up Strategy" International Journal of Recent Technology and Engineering, Volume-8, Issue-6, March 2020.

\section{AUTHORS PROFILE}

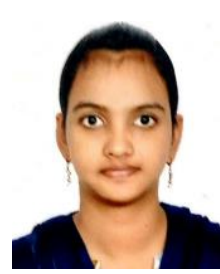

A.Navya is an Under Graduate student studying IV B.Tech Electrical and Electronics Engineering from Kallam Haranadhareddy Institute of Engineering \& Technology, Guntur, A.P., India. She is one of the toppers in the college who got meritorious scholarship and won many prizes in the technical events held at intra and inter college level. Her research interests include Power Quality and Internet of Things (IoT)

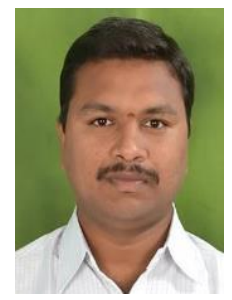

A.Panduranga Rao did his M.Tech from Jawaharlal Nehru Technological University Kakinada(JNTUK), Kakinda, Andhra Pradesh,,India in 2014 and B.Tech in Electrical Power Engineering from Jawaharlal Nehru Technological University Hyderabad (J.N.T.U.H), Hyderabad, A.P, India in 2009. He is currently Assistant Professor in EEE department at Kallam Haranadhareddy Institute of Engineering \& Technology, Guntur, A.P., India. His research interests include Power System Modeling and Control and renewable energy sources.

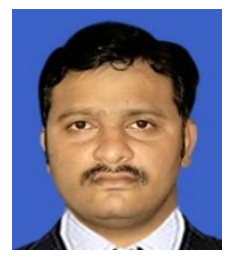

L ShanmukhaRao received Ph.D from Jawaharlal Nehru Technological University Hyderabad(JNTUH) Hyderabad,India in 2016 and M.Tech in Electrical Power Engineering from Jawaharlal Nehru Technological University (J.N.T.U), Hyderabad, A.P, India in 2006. He is currently Professor \& HOD of EEE at Kallam Haranadhareddy Institute of Engineering \& Technology, Guntur, A.P., India. His research interests include Power System Modeling and Control and renewable energy sources. He published more than 10 papers in international journals and conferences. 